\title{
Psychiatric morbidity in school going children of Bikaner
}

\author{
Bithu KS ${ }^{1}$, Chahar $\mathrm{CK}^{2}$, Singhal $\mathrm{AK}^{3}$, Khandelwal $\mathrm{S}^{4}$, Nagaraj $\mathrm{N}^{5}$, Berwal $\mathrm{PK}^{6}$ \\ ${ }^{1}$ Dr Kuldeep Singh Bithu, Assistant professor, Department of Paediatrics, ${ }^{2}$ Dr Chandra Kumar Chahar, Professor, \\ Department of Paediatrics, ${ }^{3}$ Dr Ashok Kumar Singhal, Department of Paediatrics, ${ }^{4}$ Dr Shikha Khandelwal, Department \\ of Paediatrics, ${ }^{5}$ Dr Niranjan Nagaraj, Department of Paediatrics, ${ }^{6}$ Dr Pramod Kumar Berwal, HOD, Department of \\ paediatrics. All are affiliated to SPMC, Bikaner, Rajasthan, India
}

Address for Correspondence: Dr. Niranjan Nagaraj, PBM Hospital, Bikaner, Email:getniranjan806@yahoo.com

\begin{abstract}
Background: Psychiatry morbidity is a reality in our present day society. Its measurement requires a proper, standardized, screening tool and an extensively researched classification of psychiatric ailments. This study aims to determine prevalence of psychiatric disorders and pattern of psychiatric disorders, associated socio demographic variables in school going children. Methods: The study was undertaken during 2004-2005. The sample of 500 children was drawn from children in the age group of 4-11 years from schools of Bikaner. All children in the selected sample were subjected to a screening for psychiatric symptoms by interviewing the parents of the children using childhood psychopathology score (CPMS). A score of 10 or above indicates the possibility of psychiatric morbidity among Indian children. All collected data were tabulated and statically analyzed. Results: prevalence of psychiatric disorders in children was found to be $10.2 \%$. conduct disorder was most common psychiatric disorder observed (31.4\%) followed by anxiety disorders (21.6\%).prevalence was more in children of male sex, nuclear families, higher birth orders and higher educated parents. Conclusion: epidemiological studies should start early in childhood and carried longitudinally for development of preventive, promotive and curative programme in the community.
\end{abstract}

Keywords: Psychiatry, Children, Morbidity, School, CPMS

\section{Introduction}

World health organization defines health as a state of physical, mental and social well being and not merely an absence of disease or infirmity [1]. Contrary to what many people believe, mental ill health is not limited to adults, children are afflicted with it as much. The population prevalence studies on rates of psychiatric disorders in children in India have shown that, depending upon method of assessment, definition and type of psychiatric disorders, about $7 \%$ children have a significant disorder at a given time [2,3,4]. Considering that children constitute $40 \%$ of our total population, the burden of morbidity due to psychiatric disorders in children and adolescents in country is enormous. Child psychiatry needs to be provided a status of discipline, independent and separate from adult psychiatry, paralleling a logical distinction between the disciplines of paediatrics and internal medicine.

The school plays a crucial and a formative role in the

Manuscript received: $4^{\text {th }}$ Sept 2015

Reviewed: $10^{\text {th }}$ Sept 2015

Author Corrected; $19^{\text {th }}$ Sept 2015

Accepted for Publication: $2^{\text {nd }}$ Oct 2015 development of cognitive, linguistic, social, emotional and moral functions and competencies in a child. However, in the contemporary system of education, schools have seriously marginalised and compromised their role in guiding and regulating the psychological development of children they have to cope with heavy syllabus and curricula, poor teaching facilities and highly competitive examinations. School education has become a serious stress for children and parents. School phobia, psychosomatic complaints, emotional/behavioural problems, poor sleep and appetite, difficulties in coping and declining scholastic performance are common manifestation of stress in school children.

The mental health of children is intricately rooted in the socio-cultural milieu and environment which they live. It is, therefore, imperative to consider both the risks and protective aspects of the given environment in which the children live. There are also certain innate or intrinsic factors within children such as high level of 
intelligence, an easy temperament or certain positive and protective reflexes in the environment that contribute towards their resilience. Psychiatric evaluation of children is imperative for full understanding of the health issue of the children. This study was conducted to assess psychiatric morbidity in the school children of Bikaner.

\section{Materials and Methods}

The study was undertaken during 2004-2005. The sample of 500 children was drawn from children in the age group of 4-11 years from schools of Bikaner (250 children from government schools and 250 children from private schools) randomly. A self designed performa having different socio demographic variables and a measurement schedule to assess childhood psychopathology was given to parents. All children in the selected sample were subjected to a screening for psychiatric symptoms by interviewing the parents of the children using childhood psychopathology score (CPMS).

CPMS is an Indian adaptation of Achenbach's child behaviour check list (1983) developed by Savita Malhotra et al $[4,5,6]$ consisting of 5 symptoms yielding 'Yes' or 'No' response from the interviewee. The sensitivity and specificity of the tools is $82 \%$ and $87 \%$ respectively and has been found to be valid and reliable tool for screening psychiatric morbidity among Indian children. A score of 10 or above indicates the possibility of psychiatric morbidity among Indian children. The children screened positive for psychiatric morbidity were subjected to diagnostic assessment as per criteria in ICD-10 (WHO, 1992) [7] in the presence of a consultant psychiatrist. All collected data were tabulated and stastically analysed.

\section{Results}

500 children selected for the present study were taken from government and private schools of Bikaner city. The selected children were uniformly distributed in various classes, and represent an appropriate selection of the sample. 51.6\% were males and $48.4 \%$ were females. $56.8 \%$ children were from nuclear family and $43.2 \%$ were from joint family. Majority of the children were first born $37.8 \%$ and second born $38 \%$. The parents of private schools were more educated and belonged to a higher income group of society as compared to the parents of government schools. 141 children were screened positive on childhood psychopathology measurement schedule (CPMS). On interviewing of these 141 children, 51 fulfilled one or more ICD-10 criteria for psychiatric disorders giving an overall prevalence of 10.2\%. Psychiatric problems were more in male children as compared to females (male vs female ratio 31/20). The diagnostic categories according to ICD- 10 were conduct disorder $31.4 \%$, anxiety disorder $21.6 \%$, anxiety depression $19.6 \%$, mild mental retardation $7.8 \%$, epilepsy $7.8 \%$, nocturnal enuresis $5.9 \%$, attention deficit $3.9 \%$, and moderate mental retardation $2 \%$. Conduct disorder was the most common psychiatric disorder $(31.4 \%)$. Conduct disorder were common in males and anxiety and anxiety depression disorder were common in females. Distribution of children according to birth orders showed that first born children are less affected from psychiatric problem (8.5\%) as compared to subsequently born( $100 \%$ in sixth birth order).

Table 1: Psychiatric morbidity according to CPMS and ICD-10

\begin{tabular}{|l|l|c|c|}
\hline Sr. No. & Results of sample population & No. of children & \% of cases \\
\hline 1. & Total no. of children & 500 & 100.0 \\
\hline 2. & CPMS score >10 & 141 & 28.2 \\
\hline 3. & Diagnosed according to ICD-10 & 51 & 10.2 \\
\hline
\end{tabular}

Table 2: Psychiatric morbidity according to their family configuration

\begin{tabular}{|c|c|c|c|c|}
\hline Sr. No. & Family configuration & Total children & $\begin{array}{c}\text { No. of diagnosed } \\
\text { children }\end{array}$ & $\begin{array}{c}\text { \% of diagnosed } \\
\text { children }\end{array}$ \\
\hline 1. & Joint & 216 & 20 & 9.3 \\
\hline 2. & Nuclear & 284 & 31 & 10.9 \\
\hline & Total & $\mathbf{5 0 0}$ & $\mathbf{5 1}$ & \\
\hline
\end{tabular}

$* \mathrm{p}=0.5572$ 
Psychiatric disorders were found to be more prevalent in children belonging to nuclear families (10.9\%) than joint families $(9.3 \%)$. The difference was, however, not significant.

Table 3: Prevalence of psychiatric problem and their sex wise distribution among children

\begin{tabular}{|l|c|c|c|c|}
\hline Sr. No. & Psychiatric problem & No. of children $\mathbf{( \% )}$ & No. of males & No. of females \\
\hline 1. & Anxiety & $11(21.6)$ & 4 & 7 \\
\hline 2. & Anxiety depression & $10(19.6)$ & 4 & 0 \\
\hline 3. & Attention deficit & $2(3.9)$ & 2 & 3 \\
\hline 4. & Conduct disorder & $16(31.4)$ & 13 & 2 \\
\hline 5. & Mild mental retardation & $4(7.8)$ & 2 & 0 \\
\hline 6. & $\begin{array}{c}\text { Moderate mental } \\
\text { retardation }\end{array}$ & $1(2.0)$ & 0 & 3 \\
\hline 7. & Nocturnal enuresis & $3(5.9)$ & 4 & 0 \\
\hline 8. & Epilepsy & $4(7.8)$ & $\mathbf{3 0}$ & $\mathbf{2 1}$ \\
\hline
\end{tabular}

Table 4: Psychiatric morbidity according to parents education

\begin{tabular}{|c|c|c|c|c|}
\hline Sr. No. & Parent education & Total children & $\begin{array}{c}\text { No. of diagnosed } \\
\text { children }\end{array}$ & $\begin{array}{c}\text { \% of diagnosed } \\
\text { children }\end{array}$ \\
\hline 1. & Illiterate & 27 & 1 & 3.7 \\
\hline 2. & Primary & 43 & 2 & 4.7 \\
\hline 3. & Middle & 62 & 4 & 6.5 \\
\hline 4. & Secondary & 150 & 14 & 9.3 \\
\hline 5. & Sr. Secondary & 61 & 9 & 14.8 \\
\hline 6. & Graduate & 114 & 15 & 13.2 \\
\hline 7. & Post graduate & 43 & 6 & 14.0 \\
\hline & Total & $\mathbf{5 0 0}$ & $\mathbf{5 1}$ & \\
\hline
\end{tabular}

Distribution of children according to parent education showed that psychiatric morbidity is more among children of higher educated parents

\section{Discussion}

The prevalence of childhood psychiatric disorders in school children of Bikaner has come out to be $10.2 \%$ which is in accordance with several studies conducted in western countries as well as Indian subcontinents.[8,9,10,11]. Regarding pattern of these psychiatric illnesses, conduct disorder was found to be most common $(31.4 \%)$, anxiety disorder $21.6 \%$, anxiety depression $19.6 \%$, mild mental retardation $7.8 \%$, epilepsy $7.8 \%$, nocturnal enuresis $5.9 \%$, attention deficit $3.9 \%$ and moderate mental retardation $2 \%$.

This study also suggests that males were more affected from psychiatric problem as comparison to female and on looking into diagnosis, conduct disorder were common in males and anxiety and anxiety depression disorders were common in females. Nuclear family set up was commonly associated with psychiatric morbidity as compare to joint family. An increasing birth order was also associated with psychiatric morbidity. Higher educated parents children were also found to be commonly affected from psychiatric illnesses.

\section{Conclusion}

In view of above, it is highly imperative that such epidemiological studies should start early in childhood and carried longitudinally for development of preventive, promotive and curative programme in the community.

Funding: None

Conflict of Interest: None

Permission from IRB: Yes

\section{References}

1. Park text book of Preventive and Social Medicine. $18^{\text {th }}$ ed. 2005Jan;2:13.

2. Verghese A, Beig A. Psychiatric disturbance in children--an epidemiological study. Indian J Med Res. 1974 Oct;62(10):1538-42. 
3. Deivasigamani TR. Psychiatric morbidity in primary school children -an epidemiological study. Indian J Psychiatry. 1990 Jul;32(3):235-40.

4. Malhotra S. Study of Psychological determinants of Developemental psychopathology in school childrenReport submitted to the Indian Council for Medical Research, New Delhi, 1995.

5. Achenbach TM, Edelbrock CS. Manual for Child Behaviour Checklist and Revised Child Behaviour Profile. Burlington,VT: University of Vermont, Department of psychiatry.1983.

6. Achenbach, TM., Manual for Child Behaviour Checklist/ 4-18 and 1991 profile, University of Vermint, Burlington. 1991:1-6.

7. The ICD-10 Classification of Mental and Behavioural Disorders: Clinical Description and Diagnostic guidelines. World Health Organisation.1992:225-291.
8. Roberts RE, Attkinson CC, Ftosenblatt A. Prevalence of psychopathology among children and adolescents. American Journal of psychiatry. 1998;131: 523-527.

9. Almqvist F, Puura K, Kumpulainen K, TuompoJohansson E, Henttonen I, Huikko E, Linna S, Ikäheimo K, Aronen E, Katainen S, Piha J, Moilanen I, Räsänen E,Tamminen T. Psychiatric disorders in 8-9-year-old children based on a diagnostic interview with the parents. Eur Child Adolesc Psychiatry. 1999;8 Suppl 4:17-28.

10.Ghubash R, Abou-Saleh MT. Postpartum psychiatric illness in Arab culture: prevalence and psychosocial cor relates. Br J Psychiatry. 1997 Jul;171:65-8.

11. Ollendik TH, Neville J. King PM. Fears and Phobias in children: Phenomenology, Epidemiology, and Etiology. Child and Adolescent Mental Health. 2002 Sep;7(3): 98-106.

\section{How to cite this article?}

Bithu KS, Chahar CK, Singhal AK, Khandelwal S, Nagaraj N, Berwal PK. Psychiatric morbidity in school going children of Bikaner. Pediatr Rev: Int J Pediatr Res 2015;2(3):21-24. doi: 10.17511/ijpr.2015.i03.04 